\title{
Left Atrium Emboligenic Myxoma: Case Report and Review of the Literature
}

\section{Bréhima Coulibaly ${ }^{*}$, Abdoulaye Kanté ${ }^{1,2}$, Mamadou Diakité3, Samba Sidibé3, Drissa Traoré1, Bréhima Bengaly¹, Mariam Daou, Demba Yattera1', Nouhoum Ongoïba1,2}

${ }^{1}$ Department of Thoracic and Cardiovascular Surgery, CHU Point G, Bamako, Mali

${ }^{2}$ Laboratory of Anatomy, University of Sciences, Techniques and Technologies of Bamako, Bamako, Mali

${ }^{3}$ Cardiology Department, CHU Point G, Bamako, Mali

${ }^{4}$ Department of Neurology, CHU Gabriel Touré in Bamako, Mali

Email: ^brincoulibaly@yahoo.fr

How to cite this paper: Coulibaly, B., Kanté, A., Diakité, M., Sidibé, S., Traoré, D., Bengaly, B., Daou, M., Yattera, D. and Ongoïba, N. (2021) Left Atrium Emboligenic Myxoma: Case Report and Review of the Literature. Open Journal of Thoracic Surgery, 11, 18-24. https://doi.org/10.4236/ojts.2021.111003

Received: December 1, 2020

Accepted: January 17, 2021

Published: March 10, 2021

Copyright $\odot 2021$ by author(s) and Scientific Research Publishing Inc. This work is licensed under the Creative Commons Attribution International License (CC BY 4.0).

http://creativecommons.org/licenses/by/4.0/

\begin{abstract}
Introduction: Cardiac myxomas represent the most frequent forms of primary tumors of the heart. The most frequent location is the interatrial septum. We report the clinical case of a myxoma of the left atrium and discuss its epidemiological and therapeutic aspects through a review of the literature. Observation: This was a 41-year-old female patient who presented with sudden rotational dizziness associated with vomiting. MRI revealed multiple punctiform bilateral supra and subtentorial strokes of different ages, recent and semi-recent, suggesting an embologenic etiology. Transesophageal echocardiography found a large pedunculated, homogeneous, avascular tumor hanging from the interatrial septum. The patient is operated on urgently under cardiopulmonary bypass for resection of a large tumor located in the left atrium. The pathological examination concluded with the diagnosis of myxoma of the left atrium. The postoperative follow-up was straightforward and the patient was discharged from the hospital via home hospitalization. Conclusion: The diagnosis of cardiac myxomas is suspected in the presence of symptoms associated with echocardiographic images of intracardiac masses and confirmed by histological study. Embolic accidents are one of the formidable complications of myxomas. Surgical management is urgent, especially in the presence of predictive morphological features of embolism on echocardiography.
\end{abstract}

\section{Keywords}

Myxoma of the Left Atrium, Cerebral Embolism, Interest of Trans-Esophageal Ultrasound, Surgery 


\section{Introduction}

Myxomas are benign heart tumors [1]. They are most often located in the left atrium and more rarely in the right atrium [2]. In about 10\%-15\% of cases, myxoma is diagnosed accidentally [3]. Symptoms and clinical signs are due to the obstructive nature of the mass or to embolic complications. Transthoracic echocardiography supplemented by transesophageal echocardiography generally makes it possible to confirm the presence of the mass, to determine its site and to assess whether it is vascularized or not on color Doppler, but it cannot differentiate it from a thrombus. This problem of differential diagnosis between a tissue mass and a thrombus has been resolved since the advent of cardiac MRI. The latter is able to recognize both the tissue character of the mass and some specific signs leading to the diagnosis of myxoma [4]. Coronary angiography contributes to the diagnosis of myxomas by demonstrating tumor neovascularization [5] [6]. The definitive diagnosis is based on the anatomo-histological study of the mass. Surgical excision is the only therapeutic alternative and allows total and definitive healing. We report an observation of a myxoma of the left atrium and review the literature.

\section{Clinical Observation}

It was a 41-year-old patient who regularly exercised in the gym and walked. She weighed $58 \mathrm{kgs}$ for $1.73 \mathrm{~m}$. She had a blood pressure of $122 / 76 \mathrm{~mm} \cdot \mathrm{Hg}$ and a temperature of $36.9^{\circ} \mathrm{C}$. Her history is dominated by two miscarriages and had no cardiovascular risk factors. Suddenly, she presented with spinning dizziness associated with vomiting. Notions of headache, neck pain, blurred vision, loss of urine, seizure, recent infections and head trauma were absent. She consulted in the emergency room where she is treated with thrombolysis alert. An MRI is performed, revealing multiple punctiform bilateral over and under tentorial strokes of different recent and semi-recent ages, suggesting an embologenic etiology (Figure 1).

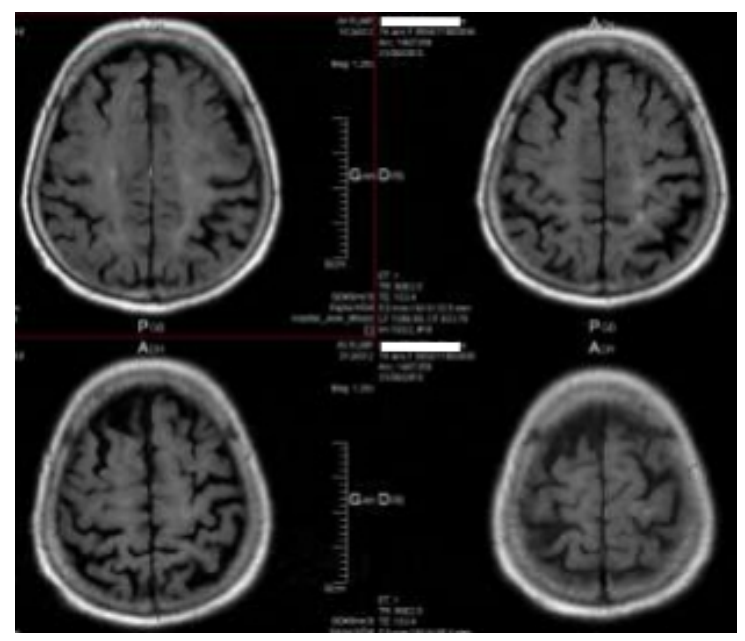

Figure 1. Showing lesions in hypersignal flair. 
The sounds of the heart were regular with no added sounds. Peripheral pulses were symmetrical and bilateral. Pleuropulmonary auscultation was bilateral and symmetrically clear. The abdomen was supple, painless and depressible. The thighs and calves were supple and painless. On the scope, the rhythm was sinus and regular. The electrocardiogram was OK. A transthoracic echocardiography is performed, not finding any abnormality, in particular no thrombus, but the transthoracic echocardiography was not very sensitive in this indication. A bolus of ASPEGIC $250 \mathrm{mg}$ is given. In this context, she was hospitalized in a neuro-vascular intensive care unit for further treatment. The Doppler of the supraortic trunks suggested a right carotid dissection at the level of the bulb with an aspect of intimal flap (Figure 2), which is why we requested an angio-CT which returned normal.

Transesophageal echocardiography found a large $20 \times 15 \mathrm{~mm}$, homogeneous and avascular tumor hanging from the interatrial septum with a pedicle-like appearance towards the left ventricle and a patent foramen ovale (Figure 3).

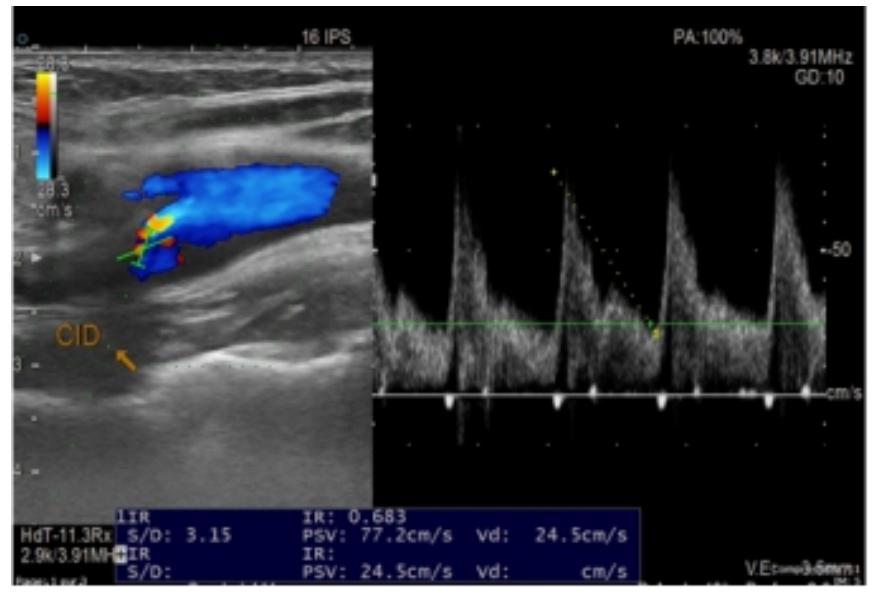

Figure 2. Doppler ultrasound of the supraortic trunks showing a stenosis with an aspect of intimal flap.

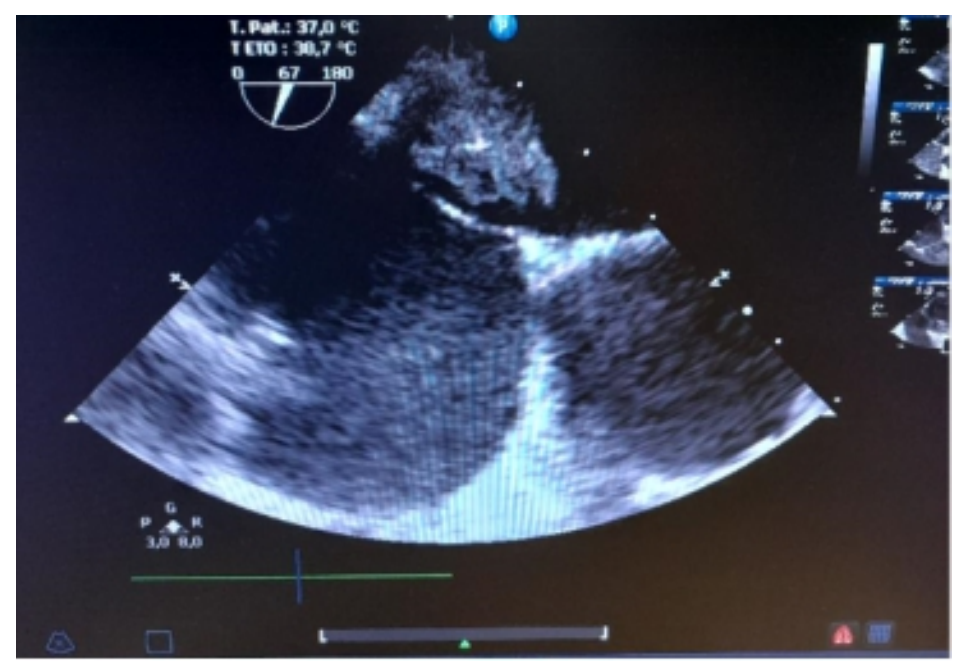

Figure 3. Transthoracic echocardiogram showing the myxoma of the left atrium. 
The chest $\mathrm{x}$-ray showed a normal-sized heart shape and good parenchymal transparency. Surgical intervention under extracorporeal circulation (ECC) successfully resected the tumor mass as well as its implantation base via the bi atrial route (Figure 3). The interatrial septum is closed with a patch of bovine pericardium thus closing the foramen ovale (Figure 4(A) and Figure 4(B)). The postoperative consequences were simple. The postoperative echocardiographic control was satisfactory and the patient was discharged on D8 postoperative.

Histological study of the mass confirmed the myxoma. Macroscopically, the mass appears gelatinous, smooth, round and crumbly. It presents areas of calcification, hemorrhage and necrosis (Figure 5), an aspect very suggestive of myxoma. Histological examination of the operative specimen confirmed the diagnosis of myxoma of the left atrium by showing florets of cells embedded in a myxoid stroma (Figure 6).
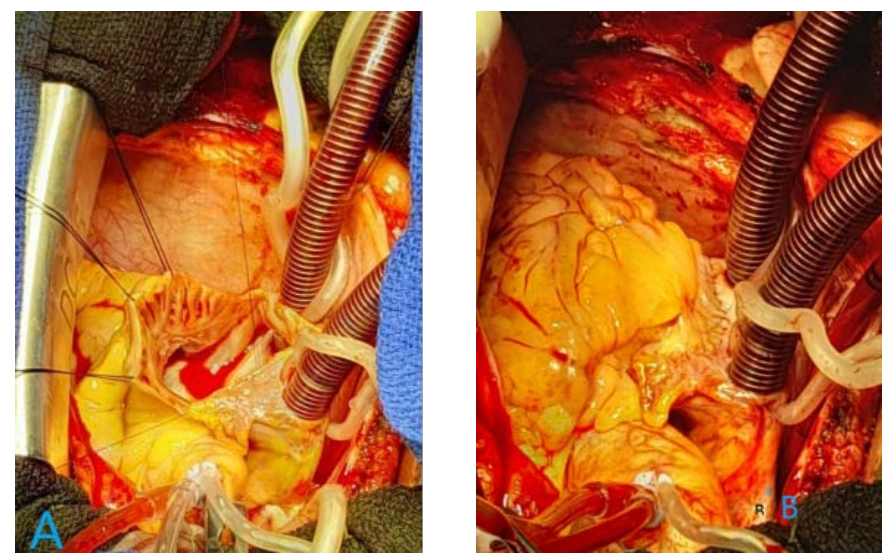

Figure 4. (A). Closure of the interatrial septum with a patch of bovine pericardium; (B). Closure of the atriotomy.

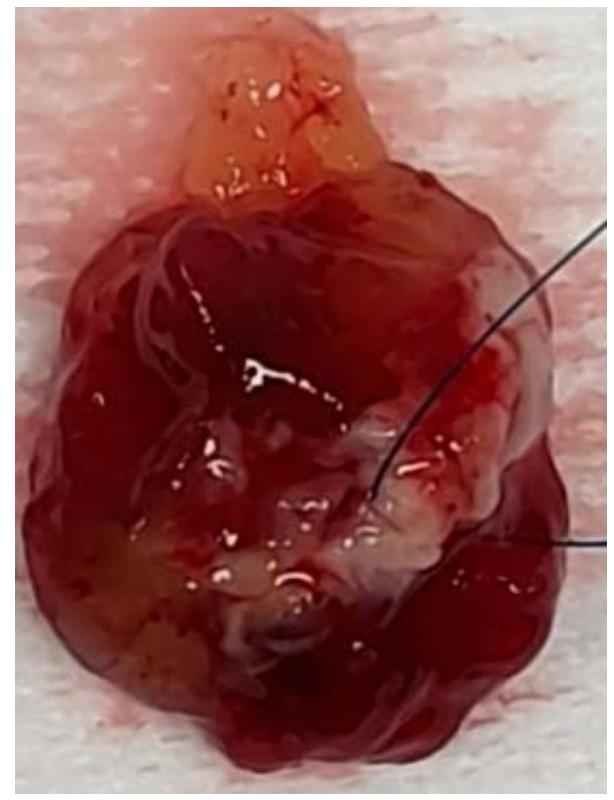

Figure 5. Operative part of the resected myxoma. 


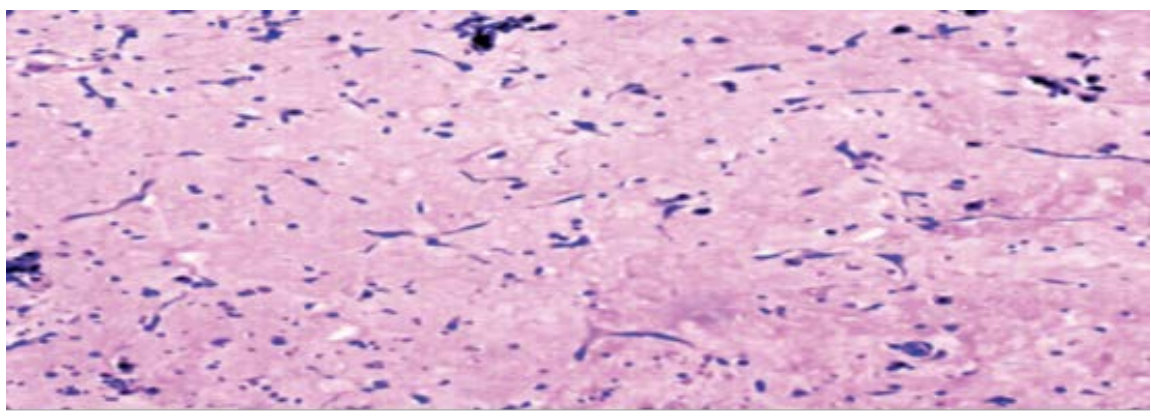

Figure 6. Showing the pathological appearance of the myxoma.

\section{Discussion}

The first autopsy description of a myxoma dates from 1845 and the first clinical diagnosis of a myxoma dates from 1952 [4]. It is a rare tumor representing $0.5 \%$ to $1 \%$ of soft tissue tumors. In its cardiac location, myxoma is by far the most common benign primary cardiopericardial tumor (91\%) [1]. The origin of myxomas has been the subject of several hypotheses, including that of development from pre-existing thrombi [5]. The commonly accepted explanation is that of a histologically benign tumor developed from "pluripotent subendocardial embryonic vestigial remnants, usually sequestered in the limbic region of the fossa ovale" of the interatrial septum (AIS) [6]. The left atrium represents $75 \%$ to $90 \%$ of myxoma locations, implantation is mainly on the interatrial septum, mitral location is very rare [7]. Intracardiac myxoma is a pathology characterized by a very large clinical polymorphism which can cause diagnostic delay, although embolic accidents represent $10 \%$ of cases [8]. The diagnosis is easily evoked by trans-thoracic echocardiography (a sensitivity of $93.3 \%$ and a specificity of $96.8 \%$ ), ETO makes it possible to specify certain areas of the tumor, in particular the attachment areas. Furthermore, the main differential diagnosis is intracavitary thrombus, adenoids and degenerative lesions of valve tissue. Surgical treatment is the only surgical alternative consisting of complete resection of the tumor and its implantation base in order to avoid any risk of recurrence. Early mortality is low less than $5 \%$. In our case, the patient presented with a transient ischemic attack due to brain embolization with a fragment detached from the myxoma [9]. The postoperative follow-up was straightforward and she was discharged from the hospital via home hospitalization. Late morbidity is dominated by the risk of tumor recurrence and the occurrence of distant metastases. The frequency of these tumor recurrences is around 2\% [10]. It is advisable to insist on a perfect surgical technique in order to prevent any risk of recurrence as well as on a regular ultrasound check of any patient operated for a cardiac myxoma.

\section{Conclusion}

Cardiac myxoma is the most common primary tumor of the heart. The diagnosis is suspected in the presence of symptoms associated with echocardiographic 
images of intracardiac masses and confirmed by histological study. Embolic accidents are one of the revealing complications of myxomas, which worsen the prognosis of these benign tumors. Surgical management is urgent, particularly in the presence of morphological characteristics predictive of embolism on echocardiography.

\section{Informed Consent of the Patient}

We, the authors of this article, certify that we have had the informed consent of the patient for the publication of this article.

\section{Contributions from Authors}

All the authors participated in the management of the patient. They participated in the design, the revision of the article. They approved the final version of the manuscript submitted for publication.

\section{Conflicts of Interest}

The authors declare no conflict of interest.

\section{References}

[1] Vaideeswar, P. and Butany, J. (2008) Benign Cardiac Tumors of the Pluripotent Mesenchyme. Seminars in Diagnostic Pathology, 25, 20-28.

https://doi.org/10.1053/j.semdp.2007.10.005

[2] Scheffel, H., Baumueller, S., Stolzmann, P., Leschka, S., Plass, A., Alkadhi, H., et al. (2009) Atrial Myxomas and Thrombi: Comparison of Imaging Features on CT. American Journal of Roentgenology, 192, 639-645. https://doi.org/10.2214/AJR.08.1694

[3] Malik, L., Borgohain, S., Gupta, A., Grover, V. and Gupta, V. (2013) Left Atrial Appendage Myxoma Masquerading as Left Atrial Appendage Thrombus. Asian Cardiovascular and Thoracic Annals, 21, 205-207. https://doi.org/10.1177/0218492312450019

[4] Li, J., Lin, F., Hsu, R. and Chu, S. (1996) Video-Assisted Cardioscopic Resection of Recurrent Left Ventricular Myxoma. The Journal of Thoracic and Cardiovascular Surgery, 112, 1673-1674. https://doi.org/10.1016/S0022-5223(96)70030-2

[5] Markel, M., Waller, B. and Armstrong, W. (1987) Cardiac Myxoma. A Review. Medicine (Baltimore), 66, 114-125. https://doi.org/10.1097/00005792-198703000-00003

[6] Goswami, K., Shrivastava, S., Bahl, V., Saxena, A., Manchanda, S. and Wasir, H. (1998) Cardiac Myxomas: Clinical and Echocardiographic Profile. International Journal of Cardiology, 63, 251-259. https://doi.org/10.1016/S0167-5273(97)00316-1

[7] Przywara-Chowaniec, B., Czarnecki, Ł., Nowalny-Kozielska, E., Gawlikowski, M., Opara, M., Puzio, A., et al. (2016) Left Atrial Myxoma in a Patient with a Biventricular Pacemaker. Kardiochirurgia i Torakochirurgia Polska, 13, 383-385. https://doi.org/10.5114/kitp.2016.64891

[8] Pinede, L., Duhaut, P. and Loire, R. (2001) Clinical Presentation of Left Atrial Cardiac Myxoma. A Series of 112 Consecutive Cases. Medicine (Baltimore), 80, 159-172. https://doi.org/10.1097/00005792-200105000-00002 
[9] Fakhari, S. and Bilehjani, E. (2016) A Large Left Ventricle Myxoma: Presenting with Epigastric Pain and Weight Loss. Case Reports in Cardiology, 2016, Article ID: 9018249. https://doi.org/10.1155/2016/9018249

[10] Kosuga, T., Fukunaga, S., Kawara, T., Yokose, S., Akasu, K., Tayama, E., et al. (2002) Surgery for Primary Cardiac Tumors. Clinical Experience and Surgical Results in 60 Patients. The Journal of Cardiovascular Surgery (Torino), 43, 581-587. 